\title{
IAMJ
}

INTERNATIONAL

AYURVEDIC

MEDICAL JOURNAL

[.]อ $(1)$

Review Article

ISSN: 2320-5091

Impact Factor: 6.719

\section{AN ANALYSIS ON MENTAL WELLBEING AND DANCE PRACTICE W.S.R TO INDIAN CLASSICAL DANCE FORMS}

\section{Nisha Kumari}

Professor and Head, Department of Roga Nidana and Vikruthi Vijnana, Yenepoya Ayurveda Medical College Mangalore, Karnataka, India

Corresponding Author: nishaathikary@gmail.com

\section{https://doi.org/10.46607/iamj.3709012021}

(Published online: January 2021)

Open Access

(C) International Ayurvedic Medical Journal, India 2021

Article Received: 29/12/2020 - Peer Reviewed: 02/01/2021 - Accepted for Publication: 04/01/2021

(A) Check for updates

\section{ABSTRACT}

Body expresses its existence because of mind that emotes, similarly mind needs body as media for the expression of its existence. Thus, Mind, Body and Spirit coordinate with each other for balancing functionality in humans and promote health. Dance is one of the mediums that bring synchronization or the coordination between them. The neurological, muscular and emotional elements of the body respond to dance in all constructive ways. The article analyzes all those components that help mind and emotions to remain well composed by regular dance practice. The focus or concentration, the mental activity and tolerance, the patience and stability are all brought into the person by practicing dance. In this study special emphasis is given to Indian classical dance forms as it involves both vigorous as well as delicate foot works and it also has vast array of hand gestures to make dancing more interesting and graceful to practice.

Keywords: Natya, Nritya, Manas, Satwa, Medha, Harsha, Prana Vata, Sadaka Pitta, Rajasa guna, Tamas, Mano Vijnana

\section{INTRODUCTION}

Dancing as well as understanding the neuroscience of it is a process of self-exploration from the inner impulses. This process connects an individual to the rhythm of nature, reminding the purpose of life and 
knowing life is beautiful and it is worth living. It can be used as therapy typically in those areas where usually verbal counseling or talks do not help, where a person encounter nonverbal issue. For many of those suffering from some sort of mental illness, often times it becomes difficult to express their feelings verbally. However, with the help of dance, those struggling are provided with an alternate artistic portal with which they can comfortably express themselves. By dancing they will be utilizing the body as a tool to express emotions and communicate feelings to which they once could not. At the same time, the "physical movement of dance" is also known to lower levels of stress, anxiety and depression. Dancing can influence perception. It encourages creativity through use of time and space. Dancing is a form of body-oriented psychotherapy that diverts mind on advanced body movement as well as programmed body movement. This will enhance salutogenesis and brain plasticity through sensory motor skill and creative program in the brain to both grey and white matter associated with motor and auditory function. Dancing is practiced as therapy in recent times named as dance therapy or dance art therapy. Dance art therapy are kinesiotheraputic that are passive and active muscular movements. It will enhance physical, mental, cognitive and emotional well-being.

Dancing is a natural phenomenon and a basic instinct. All creatures dance to express various emotions. Hence mental illness increases as we don't dance. It may be a better activity to kill their boredom and make use of time and space with more fun. It augments the mind, bursts out stress along with keeping the body physically fit. Calories burn, energy gets utilized during dancing, so naturally one will have increased appetite. A good appetite followed with good food ingestion gives good nutrition that ensures good mental health too. The natural tiredness caused due to dancing makes the person go to good sleep. Dancing influences somatization and inter perceptional sensitivity.

Empathy mediates cognition in dance improvisation. It helps understanding other's emotions and intentions. Dancers can always make affective motor decisions as movement improvisation is based on embodied cognition. In embodied cognition the body reveals the nature of the mind and motor cognition. It is that cognition which is embodied in action, social cognition, so that it helps in understanding of other's actions, emotions, and situated cognition. Mirror neurons underlie many movements, allowing dancers to subconsciously respond to stimuli from the other dancers. Empathy provides temporary structuring of movements, which allows contact improvisation. Dancers have more accurate position sense than non-dancers allowing them to rely more on position sense than vision. Physical movement of dance produces positive mental health effects. Dancing with others helps one feel a sense of connectedness. And often leads to an increase in social activity. In addition, dance classes also lend themselves to an increase in social bonds and friendships amongst dancers. This improves social wellbeing, when they find good friends to share their inner feelings. Sharing emotions keeps mental health well stabilized. A formal dance class, exercise class, or even alone in one's room could be enough to make a difference

Experts, amateurs and novices differ in their mental representations based on spatial parameters. Dancing is based on the duration of time and tempo changes with reference to foot work. The contraction and expansion of limbs, the tension and dynamics of movement which are calculative and rhythmic exercises to both brain and body. Different kinds of emotions can be expressed in different kinds of dance steps. Dance attempts to convey anger, fear, grief or joy. An automated recognition system will be attempted to find movement cues for different emotions. Fear was expressed with low fluency and many contractions in toward the body, joy with very fluent motion, and grief with frequent transitions between motion and pauses, reducing fluency.

\section{Analysis on Influence of dance on Mental activity:}

Basically, music stimulates the brain. Dancing to music activates motor and sensory coordination of the brain. Studies of professional dancers and musicians have highlighted the importance of multimodal interaction and motor-related brain regions in cerebral processing of dance and music. It is found that dancers displayed stronger synchronization at the low theta frequency. Theta synchronization is linked to emotion and memory processes which are central to all interpersonal 
interaction and self-understanding. It is also found that transcranial magnetic stimulation over the cerebellar vermis which connects the left and right hemispheres of the cerebellum has shown increased theta wave synchronization $^{2}$. The cerebellar involvement does the modulation of the core frequencies related to cognitive and emotive aspects of human behaviour. During dance there will be different synchronizing functions between different regions of the brain. Brain synchronization enables seamless cooperation and is necessary for creating both harmonic music and movement. During group or partner dancing by cooperation, the brains of two people become attuned to the same frequency of music and so will be the movement. The low-frequency brain waves of the participants in group finally become synchronized. The ability to become attuned to another person's brain frequency is essential for the function of any empathetic community. The synchronization happens between emotion and memory process. The motor cortex, located at the rear of the frontal lobe, is involved in the planning, control and execution of voluntary movements. Meanwhile, the basal ganglia, a set of structures deep within the brain, works with the motor cortex to trigger well-coordinated movements. The cerebellum, at the back of the skull, also performs several roles, including integrating information from our senses so that movements are perfectly fluid and precise. ${ }^{3}$ Dancing can reverse or slow down the aging process of brain. Learning new steps, new movements, new dance sequence, memorizing the sequence and forms will exercise more parts of brain. The brain functions in a better coordination with different regions especially mirror neuron system, premotor cortex and parietal cortex. Due to these neurological benefits the disease like Schizophrenia, Dementia, Parkinson's disease, Autism, Depression, Body dysmorphic disorder, eating disorder can be prevented. It can also prevent Multiple Sclerosis and Stroke. Pain, stress, and anxiety often go hand in hand with depression. Dance, music, and related expressive forms of therapy could help lessen mental fluctuations even before the onset of full depression. ${ }^{4}$ When we dance in a group there will be social interaction due to which depression and dementia can be prevented. It increases empathy and emotional quotient. During group dancing/ Partner dancing we communicate, share, express and improvise ourselves. When the audience give appraisals, clap/applaud for the performance...it will boost up your selfconfidence and livelihood. The stiff body usually says about possession, decreased confidence, holding on the emotion or increased inhibition. But dancing loosens them all. Soon an individual turn into extrovert. It evolves a person from concrete movements to a working metaphor. This reduces anxiety, depression, lethargy and boredom, so is the best way to kill time with fun.

\section{Dance and Hormones for mind:}

Dance is the excellent mode of expression of various kinds of emotions. It helps to emote all inhibited expressions which is very necessary to empty the negativity inside the mind. Emotions drive attention, create meaning, and have memory pathways. This is a productive combination that leads to new and novel learning. The brain is far more active and chemically stimulated when emotions are involved ${ }^{5}$. Hence dancing with expressions of emotions stimulate release of hormones and enzymes related to it. Among them important are Dopamine and norepinephrine that are released during movement or any physical activity. These emotional chemicals (hormones and neurotransmitters) enhance long-term learning when administered either before or after learning ${ }^{6}$. Learning happens as an ending result of these various psychological states. Hence dancers are always good learners. Brain is dynamic and constantly changing as a result of the world we live in and the life we lead. Brain is a cauldron of changing chemicals, electrical activity, cell growth, cell death, connectivity, and change ${ }^{6}$. Dancing is an excellent activity to vitalize chemicals and electro neural activity to keep them healthy and active.

This dynamism makes it very challenging to get clear data on what's happening in the brain. From birth to the teenage years, the brain undergoes a fourfold increase in volume (Johnson, 2001). Infants are born with roughly a trillion connections (synapses) already in place. The infant's interaction with his or her environment helps create many additional connections within the cortex. At the same time, the genetic process called 
"pruning" eliminates countless unnecessary connections. Throughout life, the brain is losing connections at the same time it is creating new connections. When this system is vulnerable to change, it is important to utilize it to bring constructive change and yield high productivity. The hypothalamus is part of the limbic system, known as the ancient "reptilian" brain, that governs our emotions and instinctual processes such as hunger, thirst and sexuality. It is here that our feelings are processed, and hormonal signals sent from the pituitary gland to the various other glands for appropriate physical and behavioural response. Dancing stimulates the endocrine system for physical and behavioural response of humans ${ }^{7}$. Adrenaline gives one a strong motive, intense power and sharp determination to stay focused at his/her task. Endorphins makes one feel happy and look cheerful, Serotonin gives sleep, relaxation and helps to achieve contempt. Dopamine provides a great physical balance and also makes one an active multitasker.

When you respond to the lyrics in the music through giving expressions while dancing, it will help explode out all the inhibited expressions. Strong mind can achieve more than a strong body. Many dreadful diseases like cancer needs a strong positive motive in the mind to get healed. Dancing helps to excrete the dirt of mind. It is a good recreational activity to prevent and get rid of unhealthy addictions. Dancing is a way of worship where you render your prayers to some force you trust that it heals all pain.

\section{Ayurveda Interpretation:}

Manas is situated all over the body. Therefore, physical exertion influences psychology. Nritya increases satwa bala (mental tolerance /stability) and makes us more composed with our temper. Nritya increases Rajasa guna which is active phase of Vata (sensory motor functions) but decreases aggressive phase of Pitta ${ }^{l}$. Natyabhyasa destroys Tamo guna (dull, inactive, lethargic, ignorant) state of mind ${ }^{1}$ and bring brightness and freshness. It helps in metabolizing toxic accumulates called Ama through biotransformation in Yakruth ${ }^{8}$ The description of Chakra in tantra shareera depicts the flow of prana (life force energy) as entering the body through seven primary energy centres. (Some systems identify as many as thirteen.) These energy centers called chakras, act like portals for the prana to flow into the body and nourish it. Each chakra is associated with a corresponding endocrine gland and related mental, emotional, or spiritual issue. As we learn from our life experiences and resolve these issues, this increases the flow of energy into the chakras, creating healing on all levels of the body mind. The emotions, thinking, and learning are all connected to each other with special reference to dancing. Most part of the brain is working while dancers execute their complex movements: fast decision-making, keen attention, monitored emotions, accessing the past alertness and recognition of surrounding potential problems, creation of immediate solutions, maintaining balance, monitoring facial expression, moving with grace, agility, and coordination, and remember sequencing (Jensen, "Arts With The Brain In Mind"). In short, while dancing, the brain is processing extreme multitasking and acting like a flight simulator (Jensen, "Arts With The Brain In Mind"). Hence there is improved cognitive development, creativity, concept of self, improved learning and competencies, vestibular action, ability to follow direction and instruction, timing and memory, and emotional expression and control while dancing.

\section{Adverse effects:}

Dance students can be excessively preoccupied with internal events like emotions, thoughts and memories. That can change the way one can perceive experiences, increasing the fear of failure and making them want to avoid uncomfortable situations. Unfortunately, those traits are associated with anxiety and depression in adolescents. The Teachers need to be aware of these tendencies so they can use healthier "behavioural techniques" that can be done by explaining how to accept failures, creating joyful environment, and more of humour during dancing. Parents can also play a role by helping their wards cope with negative emotions and by encouraging them to accept challenges. Initially avoid using dancing for competition or tournament if your ward is sensitive to failure. Avoid over physical strain as it can cause mental exhaustion and more stress. Do not get obsessed with dancing to reach perfection. Nervousness, self-conscious, pride, jealousy 
and embarrassment can be the untoward outcome of dance within a group.

\section{CONCLUSION}

Even though dancing is a personal choice, it does influence the mind or emotion of an individual. As the physical and phycological doshas are interrelated in functioning, the do influence each other in healing or improvising mental health. The resources provided by nature should be always utilized. Dance helps in utilizing physical power and mental attributes in different routine or special tasks of one's life. Dancing keeps the mind engaged and prevents unnecessary mental stress or over thinking. Focusing on Ardha shakti dancing should be a regular practice for 30 minutes at least thrice a week on morning hours.

\section{REFERENCES}

1. Srikantha Murthy KR., translator. Sushruta, Sthanam, III-1.20. Susruta Samhita. 3rd ed. Vol. 1. Varanasi: Chaukhambha Orientalia; 2007. pp. 640-4. Uttaratantra.

2. Christopher Bergland: The Athlete's Way, May 08, 2018

3. Peter Lovatt, "This Is Why We Dance,": The neuroscience-of-dance lens, 2016.dance psychologist and director of the Dance Psychology Lab at the University of Hertfordshire.

4. Hanna Poikonen. "Dance on Cortex - ERPs and Phase Synchrony in Dancers and Musicians During a Contemporary Dance Piece" University of Helsinki (May 2018)

5. Eric Jenson Copyright Arts with the Brain in Mind (C) 2001, ASCD 1703 North Beauregard St. Alexandria, VA 22311-1714

6. Eric Jensen Teaching with the Brain in Mind, 2nd Edition, ASCD 1703 North Beauregard St. Alexandria, VA 22311-1714

7. Nisha Kumari \& M Gautam Shetty: A Study on Influence Of Classical Indian Dance Practice On Cardio Respiratory Well Being. International Ayurvedic Medical Journal \{online\} 2020 \{cited October 2020\} Available from: http://www.iamj.in/posts/images/upload/4643_4648.pdf

8. Nisha Kumari \& Shetty Gautam: Biotransformation of Ama In Yakrut. International Ayurvedic Medical Journal \{online\} 2019 \{cited June, 2019\} Available from: http://www.iamj.in/posts/images/upload/916_920.pdf

\section{Source of Support: Nil Conflict of Interest: None Declared}

How to cite this URL: Nisha Kumari: An Analysis On Mental Wellbeing And Dance Practice W.S.R To Indian Classical Dance Forms. International Ayurvedic Medical Journal \{online\} 2021 \{cited January, 2021\} Available from: http://www.iamj.in/posts/images/upload/234 238.pdf 